\title{
The egg characteristics of malon broiler, Japanese quails and their cross
}

\author{
ENDANG SUJANA", ASEP ANANG, IWAN SETIAWAN, TUTI WIDJASTUTI \\ Faculty of Animal Husbandry, Universitas Padjadjaran. Jl. Raya Bandung-Sumedang Km. 21, Kampus Jatinangor, Sumedang 45363, West Java, \\ Indonesia. Tel.: +62-22-7798241, `email: endang.sujana@unpad.ac.id; endangsujana78@yahoo.co.id
}

Manuscript received: 17 September 2019. Revision accepted: 6 February 2020.

\begin{abstract}
Sujana E, Anang A, Setiawan I, Widjastuti. 2020. The egg characteristics of malon broiler, Japanese quails and their cross. Biodiversitas 21: 889-895. Research on evaluation of the characteristics of Malon broiler and Japanese quails (Coturnix coturnix japonica) eggs and on the crossbreeding between the two has been implemented in the Quail Breeding Center, Universitas Padjadjaran, Jatinangor, Indonesia. The purpose of this research is to know and evaluate the characteristics of Malon broiler and Japanese quails eggs and the crossbreeding between the two. The research used experimental method with complete random draft consisting of 4 treatments with six repeats, with each replay unit consisting of 10 grains so that the total of incubator eggs used are 240 grains. The treatment used was the breeding or marriage of Malon broiler quail $\delta$ x Malon broiler quail $\phi(\mathrm{MM})$, selected Japanese quail $\delta \mathrm{x}$ selected Japanese quail $q(\mathrm{JJ})$, Malon broiler quail $\delta \mathrm{x}$ selected Japanese quail $\rho(\mathrm{MJ})$, and Japanese selected quail $\delta \mathrm{x}$ Malon broiler quail $q$ (JM). Statistical analysis was conducted using GLM (General Linear Model) with test Duncan using SAS application programs. The observed parts are egg weight, egg shape or Shape Index (SI), specific gravity (SG), and eggshell thickness. The results showed a noticeable difference in those parts. Further research results showed that the best quality of egg incubator comes from the crossbreeding of Malon broiler quail $\hat{\partial} \mathrm{x}$ selected Japanese quail ( $(\mathrm{MJ})$, which is good for breeding quails.
\end{abstract}

Keywords: Crossbreeding, eggs characteristics, Malon quail, Japanese quail

\section{INTRODUCTION}

Along with the increasing population growth, high demand, and public awareness of the importance of the provision of food nutrition, the demands on the need for quail meat tends to increase. Fulfillment of the needs of quail can be pursued by developing broiler types to increase production scale. Breeder farms are expected to carry out proper and purposeful breeding and quail cultivation aimed at obtaining superior and continuous quality parent stock Day Old Quail (DOQ).

The availability of adequate DOQ both in quality and quantity is one of the important means of production in the cultivation of commercially-bred quails. The effort to obtain a good parent stock DOQ is closely related to the quality of the quail's precursor in commercial-based quail breeding. The quails that are cultivated by the Indonesian people are Japanese quail (Coturnix coturnix japonica), Turnix sylvatica, and Malon quail. Malon quail, derived from the abbreviation "Manuk Londo", is a cross-sexing between the local whirlwind of Coturnix coturnix japonica and French Quail. This crossbreeding is intended for the purpose of avoiding inbreeding and improving production performance. Malon quail is a type of quail that is pretty much maintained by the community, mainly designated as broiler quail because its body size is relatively larger than other local quails.

One way to achieve adequate DOQ both in quality and quantity is by selecting Japanese quail (Coturnix coturnix japonica) and Malonquail to be crossbred. Although the population is still limited, Malon quail can potentially be called broiler, because it has a greater body weight, so it is hoped that there is an excellent broiler (Sujana et al. 2017). The quail of this selection is expected to produce quails with above-average body size. Some literature suggests that the selection process in quail especially the selection of high life weights can affect the characteristics of the eggs produced. The measurement of the hatching eggs is important to determine the quality of eggs produced from quail nurseries. The characteristics of an observable egg include its exterior quality. The exterior characteristics of hatching eggs include the weight, Shape Index (SI), Specific Gravity (SG), and thickness. This characterization needs to be done to be used as a reference during egg incubator selection process, which is also can be one of hatchery successes (Nasr et al. 2015).

Knowledge of the quality of egg incubators is indispensable to quail breeding efforts. Egg quality is a collection of factors or standards that can influence and determine the quality of eggs. The quality of an egg is determined by its condition which consists of the integrity of the egg, the shape of the egg, the cleanliness of the egg, and the strength of the eggshell. The quality of the shells is a major determinant in maintaining egg quality so that it does not crack easily (Yuwanta 2010). The quality of eggs can be tested based on the testing of the whole egg (exterior) and the egg's contents or breakability (interior). The selection of egg incubators prior to establishment is important to be considered to gain maximum results. The criteria of eggs that can affect incubator results include egg weight, egg shape, the condition of the Kerabang 
(cleanliness, color, and thickness), and the condition or quality of the interior parts of the eggs.

The quality-testing of the hatching egg exterior is important to know the number of egg percentage, which is the hatching egg's worth. According to Nowaczewski et al. (2010), the quality of hatching eggs is not only influenced by genetic and environmental factors, furthermore by the age of quail. In addition, both the exterior and interior characteristics of hatching eggs, both can be influenced by the length of the egg storage period to be hatched. Some exterior quality of quail eggs can be investigated by measuring hatching eggs, egg weights, shape indexes and specific gravity. Furthermore, specific gravity can be influenced by the thickness of the shell. The exterior qualities of each quail vary. This is due to the performance and genetic differences inherited by its precursor.

An exterior measurement of egg quality is one of the parameters that can be pursued to determine the characteristics of egg seedlings and crosses. Crossbreeding is conducted to prevent the inheritance of negative traits from the parents due to same-breed mating in order to gain good qualities of the parents for its offspring. This way, the purpose of production can be optimal. Based on the description, we are interested in conducting research on the characteristics of hatching egg to produce high quality quail meat from the crossbreeding between Malon broiler quail and selected Japanese quail. New findings obtained from this research show that Malon broiler quail excels in fur color $(81.82 \%)$, body weight, and body shape. Changes in behavior patterns are also seen through a demonstration of a more sluggish behavior resembling a Malon broiler quail. The crossbred Malon broiler quail has greater weight and body size than the Japanese quail, making it more potential to be used as a broiler.

\section{MATERIALS AND METHODS}

\section{Research object}

The research objects are breeding parents of:36 male Malon broiler quail x 108 female Malon broiler quail (labeled as Malon Malon/MM),36 female Japanese quail x108 male Japanese quail (labeled as Japanese Japanese/JJ), the refining of 36 male Malon broiler quail $\mathrm{x}$ 108 selected female Japanese quail (labeled as Malon Japanese/MJ), and 36 selected male Japanese quail x 108 female Malon broiler quail (labeled as Japanese Malon/JM). Quail breeding was conducted at Quail Breeding Center, the Faculty of Animal Husbandry, Universitas Padjadjaran, Jatinangor, Sumedang, West Java, Indonesia, and eggs quality testing was conducted at the Poultry Production Laboratory of the Faculty of Animal Husbandry, Universitas Padjadjaran for 4 (four) weeks.

\section{Quail eggs}

The quail eggs used were as much as 480 grains or 20 grains from each unit of repetition. Quail egg samples were from a 13-week old well-deserved quail. This is in accordance with the results of the study of Zita et al. 2013 which shows that the characteristics of quail eggs are influenced by age and tend to be stable at week 13. The collection and testing of eggs were carried out when the quail reached 13 weeks of age. This step was conducted for 4 (four) weeks, so that every week collected 5 rounds of each unit of its repeat.

\section{Ration research}

The ration used in this research is the result of the formulation of feed materials based on the needs of the production phase of breeding, with protein content of $20.05 \%$, with $3.24 \%$ calcium and $2800 \mathrm{kcal} / \mathrm{kg}$ metabolic energy (NRC 1994). Rations were prepared with trial and error method using Excel, with the use of corn feed material, rice bran, mineral concentrate, and premix. The formulation of the breeding quail research ration and nutrient content and metabolic energy can be seen in Table 1.

\section{Saline solution}

Saline solution was used to test Specific Gravity (SG). Specific gravity of quail eggs is measured by comparison with a salt solution whose concentration has been measured using a hydrometer. The concentration distance of the specific gravity value of salt solutions commonly used in measuring the quality of quail eggs is $1.066-1.082$ with an increase of 0.004 (Santos et al. 2011).

\section{Observation of hatching eggs characteristics}

The observation on hatching eggs characteristics includes (i) Egg weight (gram): Measuring the egg weight was by weighing the hatching eggs using a digital scale, (ii) Shape Index (SI): SI was calculated by measuring the length and width of the egg using a wheeled term, with the following formula: $=($ egg width $(\mathrm{mm})) /($ egg length $(\mathrm{mm}))$ x 100, (iii) Specific Gravity (SG): SG was measured by inserting hatching eggs into a bucket containing a salt solution that had been measured using a hydrometer concentration, (iv) Shell thickness (mm): Obtained by measuring the blunt end, middle (equator), and the pointed end of the egg using calipers with a precision of $0.001 \mathrm{~mm}$, then the results were averaged.

Table 1. Ration research was done twice a day with a given amount of 27 grams per tail per day. Drinking water given was added libitum and vitamins 2 times a week

\begin{tabular}{lc}
\hline Feed material & Formulation $(\boldsymbol{\%})$ \\
\hline Corn meal & 36 \\
Rice bran & 24.4 \\
Concentrate* & 39 \\
Mineral & 0.1 \\
Premix & 0.5 \\
Total & 100 \\
\hline
\end{tabular}

* Note: Concentrate contains $36 \%$ of crude protein and $8 \%$ calcium 


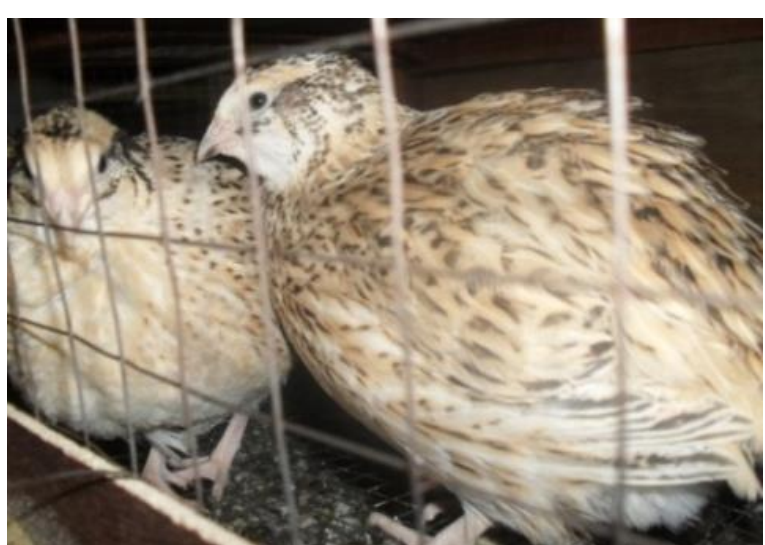

A

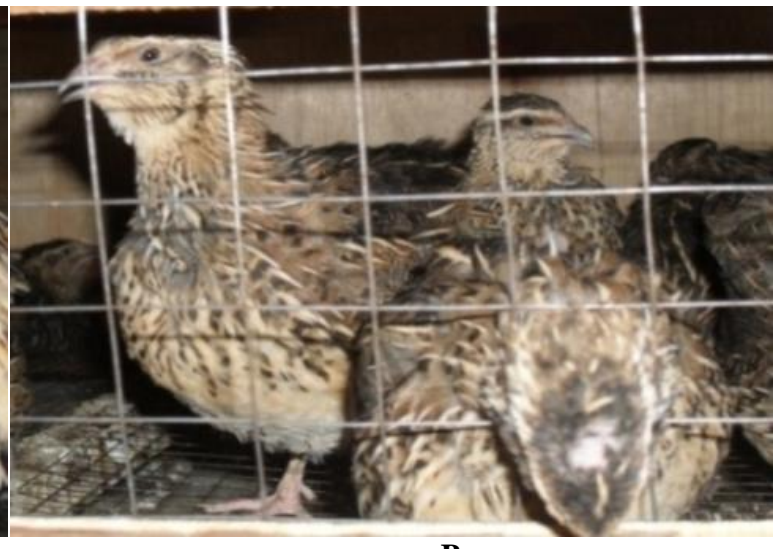

B

Figure 1. Malon (A) and Japanese quail (B) breeding parents selected

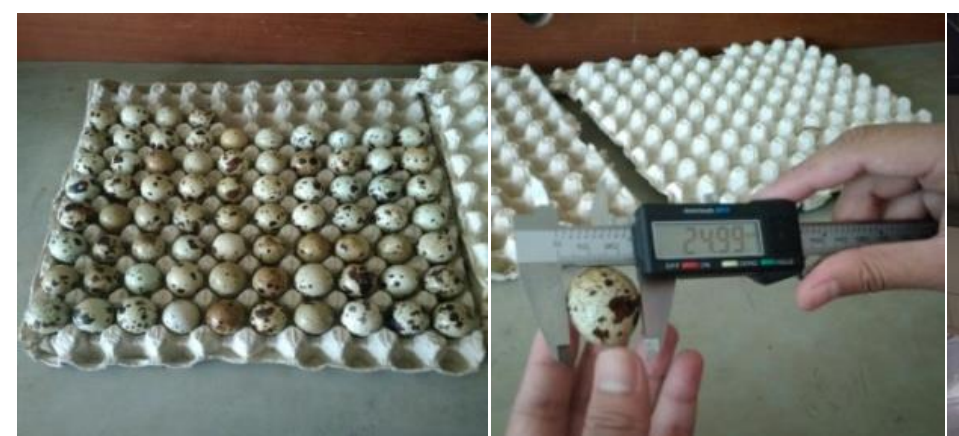

A

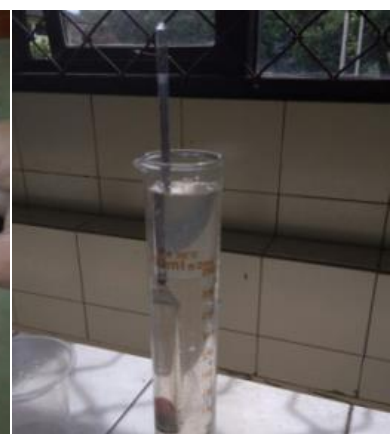

C

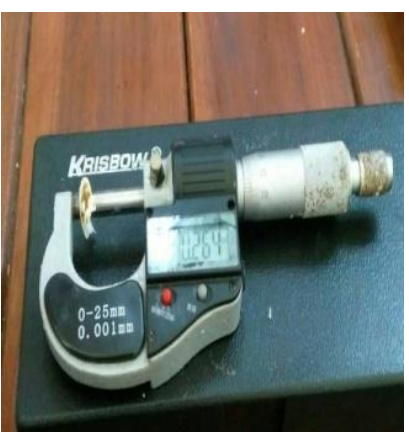

D

Figure 2. Hatching eggs (A) and equipment for measuring shape index (B), specific graphite (C) and shell thickness (D)

\section{Experimental design}

The study usedexperimental methods with complete random draft consisting of 4 treatments with six repeats. Each repeat of each replicating unit consisted of 20 eggs so that the total eggs used were 480 eggs. The treatment used was Malon broiler quail $\hat{\sigma} \mathrm{x}$ Malon broiler quail $q$ (MM), selected Japanese quail $\widehat{\delta} \mathrm{x}$ selected Japanese quail $q(\mathrm{JJ})$, Malon broiler quail $\delta \mathrm{x}$ selected Japanese quail $q$ (MJ), and selected Japanese-quail $\widehat{\partial} \mathrm{x}$ Malon broiler quail $q$ (JM). The breeding and intersecting treatment were repeated 6 times and each replay consisted of 18 female quails and 6 males. Then the eggs were observed for their characteristics ranging from egg weight, SI, SG, and shell thickness.

The mathematical models used for the complete random draft (RAL) are as follows:

$\mathrm{Yij}=\mu+\alpha \mathrm{i}+\varepsilon \mathrm{ij}$

Where:

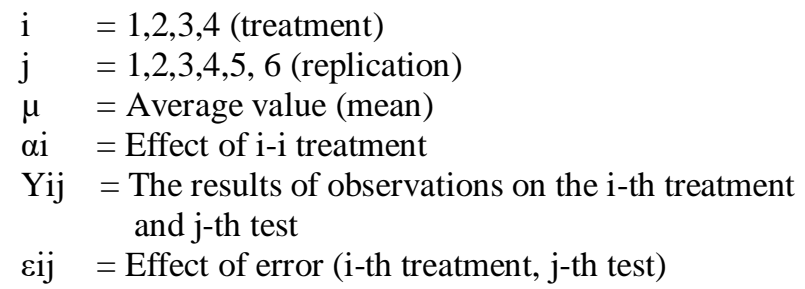

\section{Statistical analysis}

Variety analysis used GLM (General Linear Model) with post-test of Duncan test using SAS 9.0 application program. Further, standard deviation value (s) was calculated. Standard deviation is a measurement of the diversity (variation) of statistical data. According to the formula for calculating standard deviation is:

$$
S=\sqrt{\frac{\sum\left(x_{i}-\hat{x}\right)^{2}}{n-1}}
$$

\section{RESULTS AND DISCUSSION}

\section{Egg weight}

Based on Table 2, it appears that the average egg weight of the MM, JJ, MJ, and JM ranges between 11.995$12.350 \mathrm{G}$. The results of variety analysis using GLM (General Linear Model) with a posttest test Duncan using SAS application program showed a noticeable difference in the weight of the MM, JJ, MJ, and JM eggs, as shown in Table 2. The results showed high egg weights, especially in JJ and MJ. The resulting egg weights were quite high compared to the black strain-laying of quail egg (Sujana et al. 2014), with an average weight of $10.738 \mathrm{~g}$. The average 
weight of European quail eggs is $12.9 \mathrm{~g}$ (Santos et al. 2015). Quail eggs weigh about $10 \mathrm{~g}$ (about $8 \%$ of the parent body weight) to $11.91 \mathrm{~g}$ (Parizadian et al. 2011). The egg weight of the four quail strains can be seen clearly in Figure 1.

Egg weight is a trait that is influenced by genetics and protein in rations. Genetically, both types of quail and both crosses, have greater body weight properties. This large body weight is genetically influenced by the weight of the egg. The protein ration given in both types of quail is the same as containing 20 percent protein and $2800 \mathrm{kcal} / \mathrm{kg}$ metabolic energy, and already meets the need for producing eggs. Quail at laying period requires energy and protein for staple life, egg production, and growth. After basic life needs are fulfilled, the energy and protein consumed tend to be used for production rather than increasing the egg weight. Thus, the egg weight will increase according to the increase in the age of quail per laying period. According to Yuwanta (2010), the type of feed, the amount of feed, the cage environment, and the quality of feed greatly affect the weight of the resulting egg. The results of this study proved that the weight produced from the four quail strains was good.

The results of observing the quality of the exterior of quail eggs can be seen in Table 2. This weight increase demonstrates the presence of heterosis that causes livestock productivity to increase. The weight of incubator eggs affects fertility and the power of the incubator. Based on the research results conducted by Ibrahim et al. (2005), an egg with a weight range of 11.51-12.5 grams with 3-day storage period obtains the optimal value of fertility and hatchability. Furthermore, the weight of the hatching egg not only affects the hatchability but also affects the hatching weight. The heavier the weight of egg incubator the higher the DOQ produced. Butcher and Miles (2004), states that in addition to affecting hatchability, egg weight also affects hatching weight, where high egg hatching weight can produce high hatching weight as well and vice versa. Before hatching eggs with a hatching machine, it is important to do hatch egg selection based on egg weight, egg shape, cleanliness and shell thickness. Egg weight affects hatchability but does not affect fertility (Copur et al. 2010).

\section{Shape index (SI)}

The SI is a ratio between the width and the length of the egg, which represents the numerical value of the egg (Narushin and Romanov 2002). The results of SI for MM, JJ, MJ, and JMcan be seen in Table 2, which shows that the quail egg's SI ranges from 77.871-79.622. The results of various analysis using GLM (General Linear Model) with a posttest Duncan using SAS application program showed a noticeable difference in MM, JJ, MJ, and JM, as stated in Table 2. The results showed a low SI, especially in JJ and MJ. The egg's SI of the four quail strains can be seen clearly in Figure 2.

The average MM hatching egg's SI (79.622) is greater than JJ hatching egg's SI (78.259) and MJ hatching egg's SI (77.871), but similar to JM hatching egg's SI (79.438). The SI value is in line with the research results of Alasahan and Copur (2015) and Zofia et al. (2004), which show that Japanese quail SI is lower (77.23) compared to the average European quail egg SI (80.13). However, there is an average similarity of egg form between the two types of quail and the two crosses, which is equally rounded because the egg's SI exceeds 77. According to Sharma and Vohra (1980), the egg is considered round when the SI value is more than 77 , it is considered oval when the SI value is 69-77, and it is considered tapered-shaped when the SI value is less than 69. Quail eggs on average normally fall under the category of round shape. There are 3 known forms of poultry eggs, which are round, oval and oval or normal. This means that the higher the SI value, the more round the resulting egg shape.

The egg's SI reflects the form of an egg that is heavily influenced by genetic properties. SI value is one of the characteristics of poultry that is inheritable, so the eggs of each type of poultry have a type according to the shape and size of the reproduction organ, and it will thus affect the length and width of the eggs production. SI is different in each type of poultry. King'ori (2012) explains that the egg shape relies on the anatomical structure of the female poultry, such as the oviduct structure, distribution of internal organs, and the shape of the pelvic bones. According to Yuwanta (2010), the cause of the variation of SI is suspectingly a result of the rotation of eggs in the reproductive organ because of the pressure rhythm of the reproductive organ determined by the diameter of the lumen of the reproductive organ. According to Ensminger (2004), the egg shape is influenced by the width of the isthmus diameter; the wider the diameter of the isthmus, the more round the resulting egg shape. When the diameter of the isthmus is narrow, the resulting egg form tends to become oblong. Normal egg shape has a higher hatchability because it can get enough space for embryo placement in a bilateral position, so it is very important for the development of the final embryo (Lotfi et al. 2011).

Table 2. Observing the quality of the exterior of quail eggs

\begin{tabular}{lcccc}
\hline \multirow{2}{*}{ Observed (parameters) } & \multicolumn{3}{c}{ Type of quail } \\
\cline { 2 - 5 } & JJ & MM & MJcross & JMcross \\
\hline Egg weight $(\mathrm{g})$ & $12.328 \pm 0.732 \mathrm{a}$ & $12.265 \pm 0.951 \mathrm{ab}$ & $12.350 \pm 0.807 \mathrm{a}$ & $11.995 \pm 0.878 \mathrm{~b}$ \\
Shape index & $78.259 \pm 2.811 \mathrm{~b}$ & $79.622 \pm 2.542 \mathrm{a}$ & $77.871 \pm 2.539 \mathrm{~b}$ & $79.438 \pm 2.808 \mathrm{a}$ \\
Specific gravity & $1.070 \pm 0.005 \mathrm{a}$ & $1.066 \pm 0.005 \mathrm{~b}$ & $1.070 \pm 0.005 \mathrm{a}$ & $1.066 \pm 0.005 \mathrm{~b}$ \\
Shell thickness (mm) & $0.258 \pm 0.049 \mathrm{a}$ & $0.277 \pm 0.055 \mathrm{a}$ & $0.222 \pm 0.027 \mathrm{~b}$ & $0.220 \pm 0.027 \mathrm{~b}$ \\
\hline
\end{tabular}




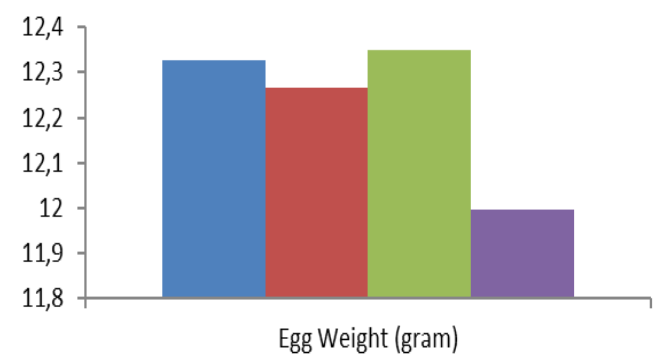

Figure 1. Effect of treatment of egg weight

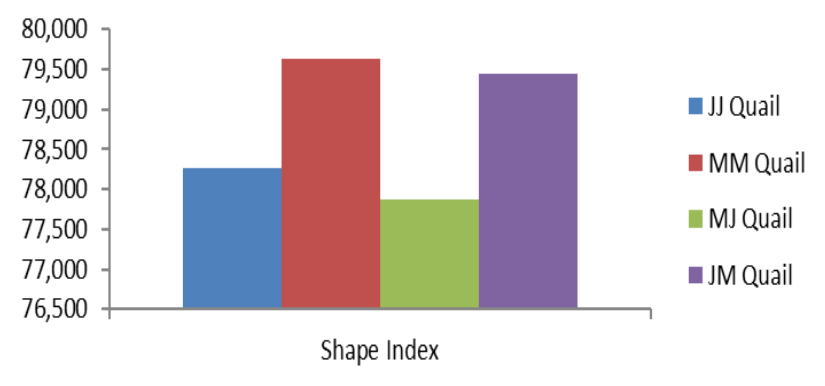

Figure 2. Effect of treatment of shape index

\section{Specific gravity}

Specific gravity (SG) is known as one of the ways in determining the thickness of the shell through the value of the index obtained by the laying of eggs in a saline solution at a certain concentration. Specific gravity measurements are important because they relate to the thickness and resistance of shells to rupture (Luciano et al. 2013). The rate of SG value of MM, JJ, and $\mathrm{MJ}$ and $\mathrm{JM}$ can be seen in Table 2, showing that the average of SG of the quail eggs ranges from 1.066-1.070. The results of various analysis using GLM (General Linear Model) with posttest test Duncan using SAS application program showed a noticeable difference in the SG of MJ and JJ, but similar to JM, as shown in Table 2. The results showed high SG, especially in JJ and MJ. The SG to four quail strains can be seen clearly in Figure 3.

The results showed high SG, especially in JJ and MJ. The SG value of the research results is not aligned with Santos et al. (2015) and Sujana et al. (2014), which state that the SG value of Malon quail egg (1.072) and is greater than the average SG value of Japanese quail egg (1.059). The difference in SG value causes different egg weights. Nordstorm and Ousterhout (1981) declare that the egg weight has a real effect on the strength of the shell and causes variation on the SG value; the higher the SG value, the thicker the eggshell. The high $\mathrm{SG}$ value indicates the high content of calcium carbonate $\left(\mathrm{CaCO}_{3}\right)$, so that the quality of the eggshell is also high (Milles and Harms 1982). SG value relates to the thickness of the Kerabang. As the SG value decreases, the number of cracked eggs will increase (Butcher and Miles 2004).

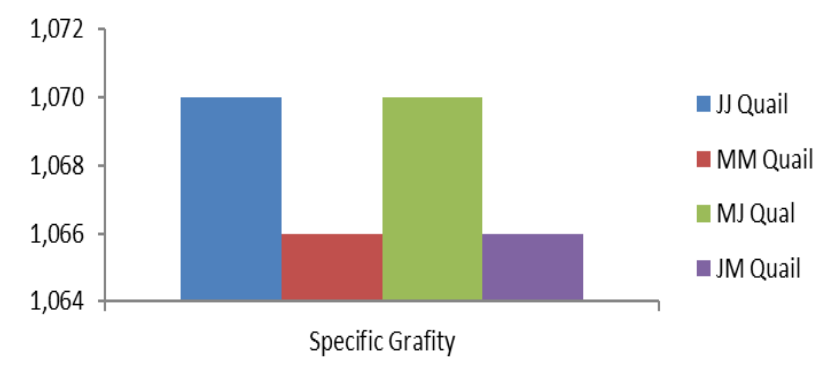

Figure 3. Effect of treatment of specific gravity

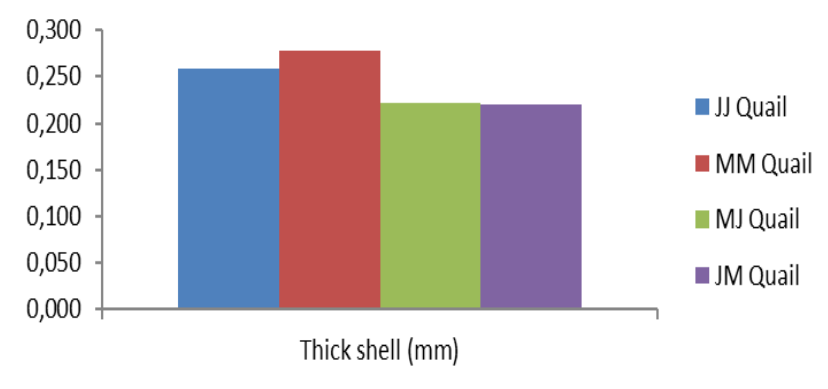

Figure 4. Effect of treatment of the thick shell

The SG value of quail eggs resulted from MJ (1.070) is higher than that of JM (1.066). The results of MJ have a good influence on the SG value instead of the results of JM. Specific gravity is a way to determine the strength of eggshells indirectly and does not damage the shell. Specific gravity is influenced by genetic, environmental and quail factors. The older the quail, the specific gravity will decrease (Nowaczewski et al. 2010). The determination of specific gravity is a method for determining eggshell thickness and shell quality (Wineland 2007). Butcher and Miles (2004) add that the value of specific gravity is related to the thickness of the shells. Other factors that influence specific gravity are egg storage time, temperature, egglaying time and content in feed (Koelkebeck 2003). Judging by the SG value in the quail egg of MJ, the quail will potentially be developed as seedlings because high SG value increases its power.

Maintaining the quality of hatching eggshells is important because it is related to hatchability (Moyle et al. 2009). As specific gravity decreases, the number of cracked eggs will increase (Butcher et al. 2004). Decreasing the value of specific gravity will cause the egg to be broken because according to Luciano et al. (2013) specific gravity related to the thickness of the shell and the resistance of the shell to break. Jacob et al. (2011) state that as eggs age, the eggs will lose fluids and their contents shrink, increasing air cavities and decreasing egg quality. Higher specific gravity values indicate that JJ quail eggs and MJ quail crosses have thicker shells. As stated by Butcher and Miles (2004), specific gravity and shell thickness are very positively correlated. 


\section{Thick eggshells}

Based on Table 2, it appears that the eggshell thickness of MM, JJ, and MJ and JM range between $0.220-0.277 \mathrm{~g}$. The results of various analysis using GLM (General Linear Model) with a posttest test Duncan using SAS application program showed a noticeable difference in the thickness of MM, JJ, and MJ and JM, as listed in Table 2. The results showed that the thickest eggshell can be seen especially in MM (0.277) and JJ (0.258). According to Zita et al. (2013), the average thickness of quail eggshell is $0.19 \mathrm{~mm}$. The study of eggshell thickness to four quail strains can be clearly seen in Figure 4.

The thickness of the shell is one of the factors affecting the quality of eggs, because the shells can protect the contents of the eggs. The thickness of the shell is much influenced by the calcium levels in the rations that determine the availability of calcium salts in the blood for the formation of eggs (Yuwanta 2010). The results of the average quail eggshell thickness produced in this study showed that the eggshell thickness in each treatment was good. According to Yuwanta (2010), the factor influencing eggshell thickness is ration consumption, where $35-75 \%$ of calcium for eggshell formation comes from the food consumed. The more rations consumed to cause the increasing availability of calcium salts in the blood for the formation of eggshells. Measurement of eggshell thickness was carried out using a screw micrometer on the blunt, middle (equator) end, the pointed end of the egg and on average (Yuwanta 2010).

Calcium is the main component in eggshell. Small grains of calcium appear on the outer side of the membrane just before the eggs leave the isthmus. It is the beginning of calcium preparation as a shell in the uterus. The calcium grain will disappear in a short time after the egg enters the shell gland. The first shell was deposited in a number of initial locations to form the inner section of the Mammillary layer consisting of 50 calcite crystals. This coating is followed by the formation of the outer part of the shell so that it forms a hard layer of calcite crystals, chalky and thick, twice in size compared to the inner shell. The intact shell consists of almost entirely calcite $\left(\mathrm{CaCO}_{3}\right)$. The eggshell is the outermost egg structure. The function of the eggshell is to reduce the physical and biological damage to the egg. \%). Eggshells are mostly formed from calcium carbonate ( $\mathrm{CaCO} 3)$. The source of $\mathrm{Ca}$ for formation comes from feed and modular bones. Calcium and modular bones are limited, therefore if the temperature is high and feed consumption decreases, the calcium needed for eggshell formation will decrease and the eggshell becomes thin and mushy (Yuwanta 2010). This is consistent with the results of research by Zita et al. (2013) that the thickness of eggshells, although often fluctuating, shows a tendency to decrease with increasing age.

The factor influencing eggshell thickness is ration consumption, where $35-75 \%$ of calcium for eggshell formation comes from the feed consumed (Yuwanta 2010). The more rations consumed to cause the increasing availability of calcium salts in the blood for the formation of eggshells.

\section{ACKNOWLEDGEMENTS}

We would like to express special thanks to the Dean of the Faculty of Animal Husbandry, Padjadjaran University (Unpad), Bandung, Indonesia for facilitating this study. We would also like to thank the students, the Labotarorium Pranata and the quail nursery cage Operators who assisted us in data collection.

\section{REFERENCES}

Alasahan S, Copur GA. 2015. Determination of some external and internal quality traits of Japanese quail (Coturnix coturnix japonica) eggs on the basis of eggshell colour and spot colour. Eurasian J Vet Sci 31 (4): 235-241.

Butcher GD, Miles RD. 2004. Egg specific gravity - Designing A Monitoring Program. http: //www.afn.org/ poultry/flkman5.htm

Copur G, Baylan M, Canogullari S. 2010. Egg weight but not egg shape index, determines the hatchability in Japanese quail (Coturnix coturnix japonica). J Anim Vet Adv 9 (13): 1890-1895.

Ensminger MA, Nesheim C. 1992. Poultry Science (animal agriculture series). 3rd ed. Interstate Publishers, Inc. Danville, IL.

Ibrahim S, SelimK, Metin B. 2005. Effects of storage and egg weight of Japenese quail eggs on hatching result. Arch Tierz 48 (5): 518-526.

Jacob J, Pescatore T, Cantor A. 2011. Avian Digestive System. University of Kentucky. College of Agriculture, Lexington.

King'ori AM. 2012. Poultry egg external characteristics: Egg weight, shape and shell colour. Res J Poultry Sci 5 (2): 14-17.

Koelkebeck WK. 2003. What is Egg Quality and Conserving It. Ilnin PooultryNet-University of Illinois, Chicago, IL.

Lotfi A, Shahryar HA, Maheri N, Abedi AS, Nahand MK. 2011. Hatching characterizes of Japanese quail (Coturnix coturnix japonica) eggs with different shape indexes. Amer-Eur J Agric Environ Sci 10 (3): 475-477.

Milles RD, Harms. 1982. Relationship between egg specific gravity and plasma phosphorus from hens fed different dietary calcium, phosphorus and sodium levels. Poultry Sci 61: 175-177.

Moyle J, Yoho D, Bramwell K. 2009. Measuring Hatching Egg Shell Quality. http://www.theopoultrysite.com/articel/1267/measuringhatching-egg-shell-quality.

Narushin VG, Romanov MN. 2002. Egg physical characteristics and hatchability. World's Poultry Sci J 58: 297-303.

Nasr MAF, El-Tarabany MS, Toscano MJ. 2015. Effects of divergent selection for growth on egg quality traits in Japanese Quail. Anim Prod Sci 56(11): A-F.

Nordstorm JQ, Oustershout LE. 1981. Estimation off shell weight and shell thickness from egg specific gravity and egg weight. Poultry Sci. 61: 1991-1995.

North MO, Bell DD. 1990. Commercial Chicken Production Manual. $4^{\text {th }}$ ed. Van Nostrand Reinhold, New York.

Nowaczewski S, Kontecka H, Rosinski A, Koberling S, Koronowski P. 2010. Eggs quality of Japanese quail depending on layer age and storage time. Foli Biologica (Kraków) 58 (3-4): 201-207.

NRC. 1994. Nutrients requirement of poultry. $9^{\text {th }}$ ed. National Academy of Science. Washington DC.

Parizadian B, Ahangari YJ, Shargh MS, Sardarzadeh A. 2011. Effects of different levels of L-carnitine supplementation on egg quality and blood parameters of laying Japanese quail. Intl J Poultry Sci 10 (8): 621-625.

Santos TC, Murakami AE, Fanhani JC, Oliveira CAL. 2011. Production and reproduction of egg and meat type quails reared in different group sizes. Braz J Poultry Sci 13 (1): 9-14.

Santos TC, Murakami AE, Oliveira CAL, Moraes GV, Stefanello C, Carneiro TV, Feitosa CCG, Kaneko IN. 2015. Influence of European quail breeders age on egg quailty, incubation, fertility and progeny performance. Braz J Poultry Sci 17 (1): 49-56.

Sharma PK, Vohra P. 1980. Relationship between egg weight, shape index, and fertility and hatchability of Japanese quail (Coturnix coturnix japonica) eggs. Indian J Poultry Sci 15: 5-10.

Sujana E, Setiawan I, Wahyuni S, Widjastuti T, Anang A. 2017. Characterization of quantitative traits of malon quail and Coturnix 
coturnix japonica selected fourth generation at the Quail Breeding Center Faculty of Animal Husbandry, Padjadjaran University. Proceedings of the National Seminar on Sustainable Animal Husbandry 9: Faculty of Animal Husbandry, Padjadjaran University. Bandung. [Indonesian]

Sujana E, Widjastuti T, Anang A. 2014. Characteristics of quail eggs exterior quality basic population in brown and black fur color lines a quail nursing Centers in Padjadjaran University campus Jatinangor. National Seminar on Sustainable Animal Husbandry 6. Faculty of Animal Husbandry, Padjadjaran University, Jatinangor. November 14, 2014. [Indonesian]
Wineland MJ. 2007. Specific gravity determination for hatching eggs. http://www.ces.ncsu.edu/depts/poulsci/tech_manuals/gravity_determi nation.html.

Yuwanta T. 2010. Eggs and Egg Quality. Gadjah Mada University Press. Yogyakarta. [Indonesian]

Zita L, Ledvinka Z, Klesalova L. 2013. The effect of the age of Japanese quails on certain egg quality traits and their relationships. Vet Archiv 83: 223-232.

Zofia T, Danuta S, Marek L, Alicja D, Majewska D, Kurzawa J. 2004. Effect of the origin of quails on their utility type and selected egg quality traits. Electr J Polish Agric Univ 7 (2): \#07. http: //www.ejpau.media.pl/volume7/issue2/animal/art-07.html. 